\title{
Semisynthesis of novel monacolin J derivatives: hypocholesterolemic and neuroprotective activities
}

\author{
Sonia Campoy ${ }^{1}$, Saleta Sierra ${ }^{2}$, Beatriz Suarez ${ }^{1}$, Maria C Ramos ${ }^{2}$, Javier Velasco ${ }^{1,2}$, Javier S Burgos ${ }^{2}$ \\ and Jose L Adrio ${ }^{1,3}$ \\ A fungal strain able to naturally accumulate large amounts of monacolin $\mathrm{J}$ was improved by $\mathrm{N}$-methyl- $\mathrm{N}$-nitro- $\mathrm{N}$-nitrosoguanidine \\ mutagenesis and genetic disruption of the lov $F$ gene. Semisynthesis was then used to produce novel statins by attaching \\ different side chains at the $\mathbf{C} 8$ hydroxyl residue. In vitro hypocholesterolemic and neuroprotection assays showed that \\ one derivative (NST0037) had a very low 3-hydroxy-3-methylglutaryl CoA reductase $\mathrm{IC}_{50}$ and high protection rate for \\ oxidative-stress-induced neuron cell death.
}

The Journal of Antibiotics (2010) 63, 499-505; doi:10.1038/ja.2010.76; published online 21 July 2010

Keywords: hypocholesterolemic; monacolin J; neuroprotection; statins

\section{INTRODUCTION}

Lovastatin and its analogs are inhibitors of 3-hydroxy-3-methylglutaryl CoA reductase (HMG-CoA reductase), the enzyme that catalyzes the rate-limiting step of cholesterol biosynthesis. These compounds, the early members of statins family, are secondary metabolites produced by several fungal genera such as Penicillium, Monascus, Aspergillus and Trichoderma, among others. ${ }^{1,2}$ Statins are the most effective lipid-lowering agents in the market, being commonly used to prevent coronary heart disease.

In the last years, a close correlation between hypercholesterolemia and Alzheimer's disease $(\mathrm{AD})$ has been reported. ${ }^{3}$ In fact, several studies have examined the role of statins in the prevention of dementia and treatment of established $\mathrm{AD}$. Results concluded that patients that had taken statins showed a $70 \%$ lower prevalence of $\mathrm{AD} .^{4-6}$

All natural statins have a main polyketide structure (monacolin $\mathrm{J}$ ) to which varied side chains are linked at C6 and C8 positions, and a $\beta$-hydroxylactone. The latter is present as the corresponding $\beta$-hydroxy acid in the active form of this class. The inhibition of HMG-CoA reductase is due to the structural similarity of HMG-CoA, the natural substrate of the enzyme, and the acid form of the statins. ${ }^{7}$

In the final step of the lovastatin biosynthesis pathway, the 2-methylbutyrate side chain is synthesized by lovastatin diketide synthase, the product of $l o v$ F gene. ${ }^{8}$ The 2-methylbutyrate is covalently attached to the acyl carrier domain of lov $\mathrm{F}$ through a thioester linkage. Then an acyltransferase, made by $l o v \mathrm{D}$, is able to transfer the side chain selectively to the $\mathrm{C} 8$ hydroxyl group from lovastatin diketide synthase to yield lovastatin. Inactivation of either $l o v \mathrm{D}$ or $\operatorname{lov} \mathrm{F}$ leads the accumulation of the precursor monacolin $\mathrm{J}$.
Therefore, monacolin $\mathrm{J}$ is a key intermediate that could be used as a lead to produce novel derivatives by semisynthesis. Currently, monacolin $\mathrm{J}$ is obtained from lovastatin through chemical processes involving long alkali treatments, very low to high temperatures and organic solvents. ${ }^{9,10}$ Such processes must be carefully controlled to avoid undesired side products formation and to reach a high yield. To develop a new biological and more environmentally friendly route, we developed a strategy to directly produce monacolin J by fermentation. Such strategy is based on the disruption of the lov $\mathrm{F}$ gene of a fungal strain leading to transformants able to accumulate large amounts of this intermediate. Monacolin J was extracted and purified from fermentation broths and derivatives were obtained by semisynthesis after chemical attachment of different side chains to the C8 hydroxyl group. These novel compounds were screened for their hypocholesterolemic and neuroprotective activities.

\section{MATERIALS AND METHODS}

Microorganisms, culture conditions and cloning vectors

Escherichia coli XL-1 Blue (ECOS Blue; Biomedal, Sevilla, Spain) and E. coli $\mathrm{DH} 5 \alpha^{9}$ were used as a host strains for gene cloning and propagation of vector molecules. These strains were grown in Luria-Bertani.

Candida albicans CECT 1002 was used in bioassay. Aspergillus terreus ATCC 20542 was obtained from the American Type Culture Collection (Manassas, VA, USA). Neosartorya stramenia CECT 20742 was isolated in our laboratory. N. stramenia $34-211$ is a mutant strain obtained from N. stramenia CECT 20742, which was used as recipient strain for transformation experiments. Fungal strains were grown on MEA medium ( $1.5 \%$ malt extract, $0.1 \%$ bactopeptone, $2 \%$ glucose, $2 \%$ agar, $\mathrm{pH} 5.6)$ for $7-8$ days at $28^{\circ} \mathrm{C}$. Spores were harvested with a sterile solution ( $2 \%$ Tween 20$)$, washed and inoculated into

${ }^{1}$ Biolndustrial Division, Neuron BPh, Granada, Spain and ${ }^{2}$ BioPharma Division, Neuron BPh, Granada, Spain

${ }^{3}$ Dedicated to Arny (Professor Arnold L Demain), a master, a teacher and a friend. Thanks for being an amazing model of good, hard and dedicated work to all of us. Congratulations on your 60 years of scientific career!

Correspondence: Dr JL Adrio, Biolndustrial Division, Neuron BPh, S.A., Avenida de la Innovacion, 1, Edificio BIC-Granada, PTCS, Armilla, Granada 18100, Spain.

E-mail: jladrio@neuronbp.com

Received 29 March 2010; revised 7 June 2010; accepted 9 June 2010; published online 21 July 2010 
$50 \mathrm{ml}$ YM medium ( $0.3 \%$ yeast extract, $0.3 \%$ malt extract, $0.5 \%$ meat peptone, $2 \%$ glucose). Liquid culture was incubated at $28^{\circ} \mathrm{C}$ at 250 r.p.m. for $48 \mathrm{~h}$. Grown culture $(1 \mathrm{ml})$ was used to inoculate $10 \mathrm{ml}$ of Medium 1 broth $(5 \%$ glucose, $2 \%$ yeast extract, $2 \%$ tomato paste, $2 \%$ oatmeal, $1 \%$ sodium acetate, $0.5 \%$ ammonium sulfate, $0.2 \% \mathrm{KH}_{2} \mathrm{PO}_{4}, 1 \%$ trace elements solution ( $\mathrm{pH} 7.0$ ). Composition of trace elements solution (by liter): $1 \mathrm{~g} \mathrm{FeSO}_{4} \cdot 7 \mathrm{H}_{2} \mathrm{O}, 1 \mathrm{~g}$ $\mathrm{MnSO}_{4} \cdot 4 \mathrm{H}_{2} \mathrm{O}, 25 \mathrm{mg} \mathrm{CuCl}_{2} \cdot 2 \mathrm{H}_{2} \mathrm{O}, 100 \mathrm{mg} \mathrm{CaCl}_{2} \cdot 2 \mathrm{H}_{2} \mathrm{O}, 56 \mathrm{mg} \mathrm{H}_{3} \mathrm{BO}_{3}$, $\left.19 \mathrm{mg}\left(\mathrm{NH}_{4}\right)_{6} \mathrm{Mo}_{7} \mathrm{O}_{24} \cdot 2 \mathrm{H}_{2} \mathrm{O}, 200 \mathrm{mg} \mathrm{ZnSO}_{4} \cdot 7 \mathrm{H}_{2} \mathrm{O}\right)$ and this culture was incubated at $28^{\circ} \mathrm{C}$ at 250 r.p.m. for the indicated times. pUC18Not, a $2715 \mathrm{pb}$ plasmid derived from pUC18 vector (GenBank/EMBL sequence accession number L09136, Cambridge, UK), was used to clone the N. stramenia CECT 20742 lov F gene fragment. yT\&A Cloning Vector Kit (Yeastern Biotech, Taipei, Taiwan) was used to clone the A. terreus ATCC $20542 \operatorname{lov} \mathrm{F}$ gene fragment. pAN7-1 $1^{11}$ was used to obtain the hygromycin-resistance cassette (A. nidulans gpdA promoter-hyg ${ }^{\mathrm{R}}$ gene from E. coli-A. nidulans trpC terminator).

\section{Mutation with $\mathrm{N}$-methyl- $\mathrm{N}^{\prime}$-nitro- $\mathrm{N}$-nitrosoguanidine}

Spore suspensions were treated with $2.7 \mathrm{~mm} N$-methyl- $N^{\prime}$-nitro- $N$-nitrosoguanidine for $150 \mathrm{~min}$. Under these conditions mortality was above $95 \%$. Spores were washed several times with sterile water and grown on plates of MEA medium at $28^{\circ} \mathrm{C}$ for $4-5$ days.

\section{Construction of pNBP.003 and pNBP.004 vectors}

These plasmids were constructed to disrupt the $l o v \mathrm{~F}$ gene encoding lovastatin diketide synthase involved in the transfer of the methylbutyryl side chain to monacolin $\mathrm{J}$ to give lovastatin. To amplify the $l o v \mathrm{~F}$ gene fragment, we designed two oligonucleotides according to conserved sequences from $\operatorname{lov} \mathrm{F}$ from A. terreus and A. niger. To introduce the SacI/KpnI restriction sites at the ends of amplified fragment, we changed some nucleotides that have been identified in boldface and underlined: lovF-Sac ( $5^{\prime}$-gga gag gga gct cca gcg t $-3^{\prime}$ ) and lovF-Kpn (5'- acg cat ggt acc tag taa tcc g- $\left.3^{\prime}\right)$. Optimized amplification reaction contained $1 \mu \mathrm{l}$ of genomic DNA, $1 \times$ Herculase II Fusion DNA Polymerase Buffer, $0.4 \mu \mathrm{M}$ of each primer, $250 \mu \mathrm{M}$ each dNTP, $5 \%$ DMSO, $3 \mathrm{~mm} \mathrm{MgCl} 2,1 \mu$ l of Herculase II Fusion enzyme (Stratagene, Santa Clara, CA, USA) in total reaction volume of $50 \mu \mathrm{l}$. The reaction mixture was subjected to the following program (in a iCycler Thermal Cycler; Bio-Rad, Hercules, CA, USA): $98^{\circ} \mathrm{C}, 4 \mathrm{~min} ; 35$ cycles $\left(98^{\circ} \mathrm{C}\right.$, $\left.30 \mathrm{~s} ; 56^{\circ} \mathrm{C}, 30 \mathrm{~s} ; 72^{\circ} \mathrm{C}, 120 \mathrm{~s}\right) ; 72^{\circ} \mathrm{C}, 10 \mathrm{~min}$.

The $2978 \mathrm{pb}$ PCR product of N. stramenia CECT 20742 was purified and digested with $\mathrm{Kp} n \mathrm{I} / \mathrm{SacI}$. This fragment was cloned in $\mathrm{Kp} n \mathrm{I} / \mathrm{SacI}$ restriction sites of pUC18Not plasmid to give plasmid pNBP.001. The $4 \mathrm{~kb}$ hygromycinresistance expression cassette was extracted from pAN7-1 plasmid (BglII/XbaI) and was cloned into BglII digested pNBP.001 to give plasmid pNBP.003 (Figure 1).

The $3297 \mathrm{pb}$ PCR product of A. terreus ATCC 20542 was cloned in the yT\&A cloning vector (Yeastern Biotech) to give plasmid pNBP.002. Then, this fragment was digested with $\mathrm{NcoI}$ and cloned into the hygromycin-resistance expression cassette in pNBP.001 to give pNBP.004 (Figure 1).

\section{Transformation of N. stramenia protoplasts}

Protoplasts preparation. N. stramenia 34-211 was grown in Power medium ${ }^{12}$ at $28^{\circ} \mathrm{C}$ for $4-5$ days. Spores of two plates were harvested, concentrated to $2 \mathrm{ml}$ and incubated at $50^{\circ} \mathrm{C}$ for $90 \mathrm{~s}$. Then, were transferred to $100 \mathrm{ml}$ of YM broth $\left(3 \mathrm{gl}^{-1}\right.$ yeast extract, $3 \mathrm{gl}^{-1}$ malt extract, $5 \mathrm{gl}^{-1}$ meat peptone and $20 \mathrm{gl}^{-1}$ glucose) and incubated about $15-16 \mathrm{~h}$ at $28^{\circ} \mathrm{C}$ and 250 r.p.m. The culture was centrifuged to 8000 r.p.m. for $20 \mathrm{~min}$, the mycelium was suspended in TP $(50 \mathrm{~mm}$ potassium phosphate buffer ( $\mathrm{pH} 5.8$ ), $0.5 \mathrm{M} \mathrm{KCl}, 0.1 \mathrm{M} \mathrm{MgSO}_{4} \cdot 7 \mathrm{H}_{2} \mathrm{O}$ ) with $0.1 \mathrm{M}$ DTT and incubated in the same conditions for $2 \mathrm{~h}$. The mycelium was filtered ( $10 \mu \mathrm{m}$ nylon filter), suspended in $10 \mathrm{ml}$ TP with $20 \mathrm{mg} \mathrm{ml}^{-1}$ lysing enzymes from Trichoderma harzianum (Sigma, Madrid, Spain) and $1000 \mathrm{Uml}^{-1}$ of $\beta$ glucuronidase Type HP-2 from Helix pomatia (Sigma) and incubated at $28^{\circ} \mathrm{C}$ and 90 r.p.m. for $1-2 \mathrm{~h}$. The protoplasts were filtered through a $10 \mu \mathrm{m}$ nylon filter and washed three times with KCM solution $\left(0.6 \mathrm{M} \mathrm{KCl}, 50 \mathrm{mM} \mathrm{CaCl}_{2}, 10 \mathrm{~mm}\right.$ MES ( $\mathrm{pH} 5.8)$ ). The washed protoplasts were suspended with 1 vol KCM solution and $0.2 \mathrm{vol}$ PCM solution (50\% PEG 6000, $50 \mathrm{mM} \mathrm{CaCl}_{2}, 10 \mathrm{mM}$ MES ( $\mathrm{pH}$ 5.8)).
Transformation. Protoplasts suspension $(100 \mu \mathrm{l})$ were mixed with $10 \mu \mathrm{l}$ of DNA and incubated on ice for $25 \mathrm{~min}$. Then $500 \mu \mathrm{l}$ of PCM was added, mixed and incubated at RT for $30 \mathrm{~min}$. Finally, $600 \mu \mathrm{l}$ of KCM solution was added and hygromycin B-resistant transformants were selected on plates of SDA sucrose medium ( $4 \%$ glucose, $1 \%$ neopeptone (Difco, Franklin Lakes, NJ, USA), 2\% agar (Difco), $10.3 \%$ sucrose ( $\mathrm{pH}$ 5.6)) containing $200 \mu \mathrm{g} \mathrm{m}^{-1}$ hygromycin B after incubation at $28^{\circ} \mathrm{C}$ for $5-6$ days.

\section{Bioassay}

Production of monacolin J was tested by agar-diffusion bioassay. Agar plugs of N. stramenia 34-211 mutants grown on MEA plates were placed on the surface of plates seeded with C. albicans. Plates were incubated at $28^{\circ} \mathrm{C}$ for $12 \mathrm{~h}$ and zones of growth inhibition were recorded.

The $\beta$-hydroxy acid form of statins (lovastatin, mevastatin, simvastatin) is known to have antifungal activity and growth inhibition zones are produced on the bioassay plates. In contrast, monacolin J does not have such antifungal activity and therefore no inhibition halos are observed.

\section{Analytical methods}

Cultures were extracted with EtOAc and dried extracts were resuspended in EtOH. Lovastatin and monacolin J were quantified by UPLC-SIR-MS using an Acquity BEH C18 column (particle size $1.7 \mu \mathrm{m}$, length $2.1 \times 100 \mathrm{~mm}$ ) (Waters Cromotografía SA, Cerdanyola del Vallès, Spain). Two solvents were used as mobile phase: $0.1 \%$ formic acid in water $(\mathrm{A})$ and $\mathrm{CH}_{3} \mathrm{CN}(\mathrm{B})$. The gradient began with $25 \% \mathrm{~B}$ and ended with $80 \%$ B for $6.5 \mathrm{~min}$, at a flow rate of $0.3 \mathrm{ml} \mathrm{min}^{-1}$.

Quantification of monacolin $\mathrm{J}$ and lovastatin from culture samples was carried out by UPLC (see above) using calibration curves representing log area (commercial standards) versus concentration. Curves for the lactone and acidic forms were prepared from commercial standards. Regression coefficients $\left(R^{2}\right)$ were 0.996 and 0.997 for monacolin J, and 0.991 and 0.996 for lovastatin, respectively.

Structure of novel monacolin J derivatives was analyzed in a Bruker AV-300/ $500 \mathrm{MHz}$ spectrometer (Bruker Española SA, Rivas Vaciamadrid, Spain) by MNR- $\mathrm{H}^{-1}, \mathrm{MNR}-\mathrm{C}^{13}$ and DEPT. Bidimensional techniques $\mathrm{H} / \mathrm{H}$ (COSY and TOCSY) and H/C (HSQC and HMBC) were also used.

\section{Semisynthesis of novel monacolin J derivatives}

N. stramenia 34-211 (T-64) was grown on MEA medium for 7-8 days at $28^{\circ} \mathrm{C}$. Spores were harvested with a sterile solution ( $2 \%$ Tween 20$)$, washed and inoculated into flasks containing $100 \mathrm{ml} \mathrm{YM}$ medium. Liquid culture was incubated at $28^{\circ} \mathrm{C}$ at 250 r.p.m. for $48 \mathrm{~h}$. Twenty milliliters of such seed culture were used to inoculate sixteen 1 liter flasks each containing $200 \mathrm{ml}$ of Medium 1 broth and were incubated at $28^{\circ} \mathrm{C}, 250$ r.p.m. for $192 \mathrm{~h}$. In these conditions, N. stramenia 34-211 (T-64) produces mainly monacolin J. The culture was acidified to $\mathrm{pH} 3$ with TFA ( $1 \mathrm{~h}$, room temperature, on shaking) and extracted by stirring with EtOAc $(5 \times 400 \mathrm{ml}$, for $1 \mathrm{~h}$ each), the combined extracts were dried $\left(\mathrm{Na}_{2} \mathrm{SO}_{4}\right)$, followed by evaporation and redissolving in $40 \mathrm{ml}$ EtOAcl $\mathrm{n}$-hexane (20:80). Then it was passed through a silica gel column $(1.2 \times 20 \mathrm{~cm})$. The lactone monacolin J was eluted with EtOAc/n-hexane (45:55), vacuum evaporated, dissolved in $10 \mathrm{ml}$ of acetone and stored at $4{ }^{\circ} \mathrm{C}$ overnight. The precipitate was filtered, washed with $2 \mathrm{ml}$ of acetone followed of $2 \mathrm{ml}$ of $\mathrm{n}$-hexane and was dried at room temperature. The monacolin J was dissolved in $20 \mathrm{ml}$ of $\mathrm{MeOH}$, decolorized by treatment with $10 \mathrm{~g}$ of activated charcoal, crystallized at $-20{ }^{\circ} \mathrm{C}$ with $\mathrm{EtOH} / \mathrm{EtOAc}$ and dried at room temperature. Finally $10.25 \mathrm{~g}$ of monacolin $\mathrm{J}$ with purity higher than $99.4 \%$, according to UPLC-PDA-MS analysis, was obtained.

Monacolin J derivatives were obtained by a semisynthetic process. Purified monacolin $J$ was subjected to selective silylation of the C13 alcohol with trimethyl chlorosilane or $t$-butyl dimethyl chlorosilane, followed by acylation of C8 alcohol with different side chains (Figure 2) and deprotection of C13 alcohol with fluoride salts (for example, TBAF). Simvastatin (Sequoia Research Products, Pangbourne, UK) was used as a positive control.

\section{In vitro assays of HMG-CoA reductase inhibition}

The activity of the novel derivatives in inhibiting HMG-CoA reductase was analyzed in comparison to simvastatin. Stock solutions were previously treated 
a

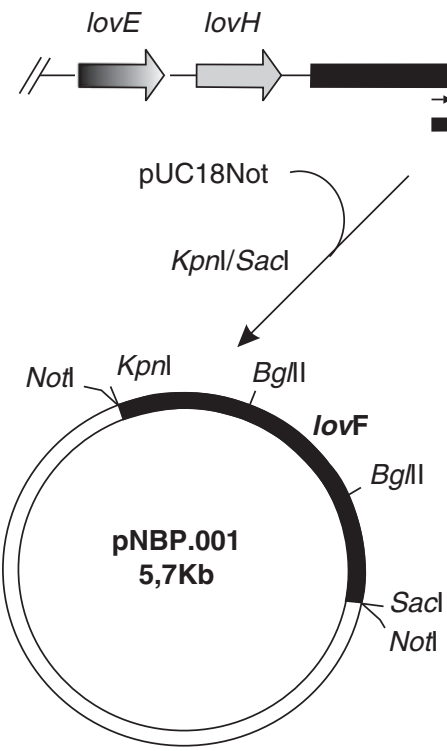

lovF

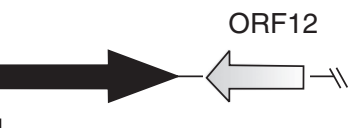

ORF12
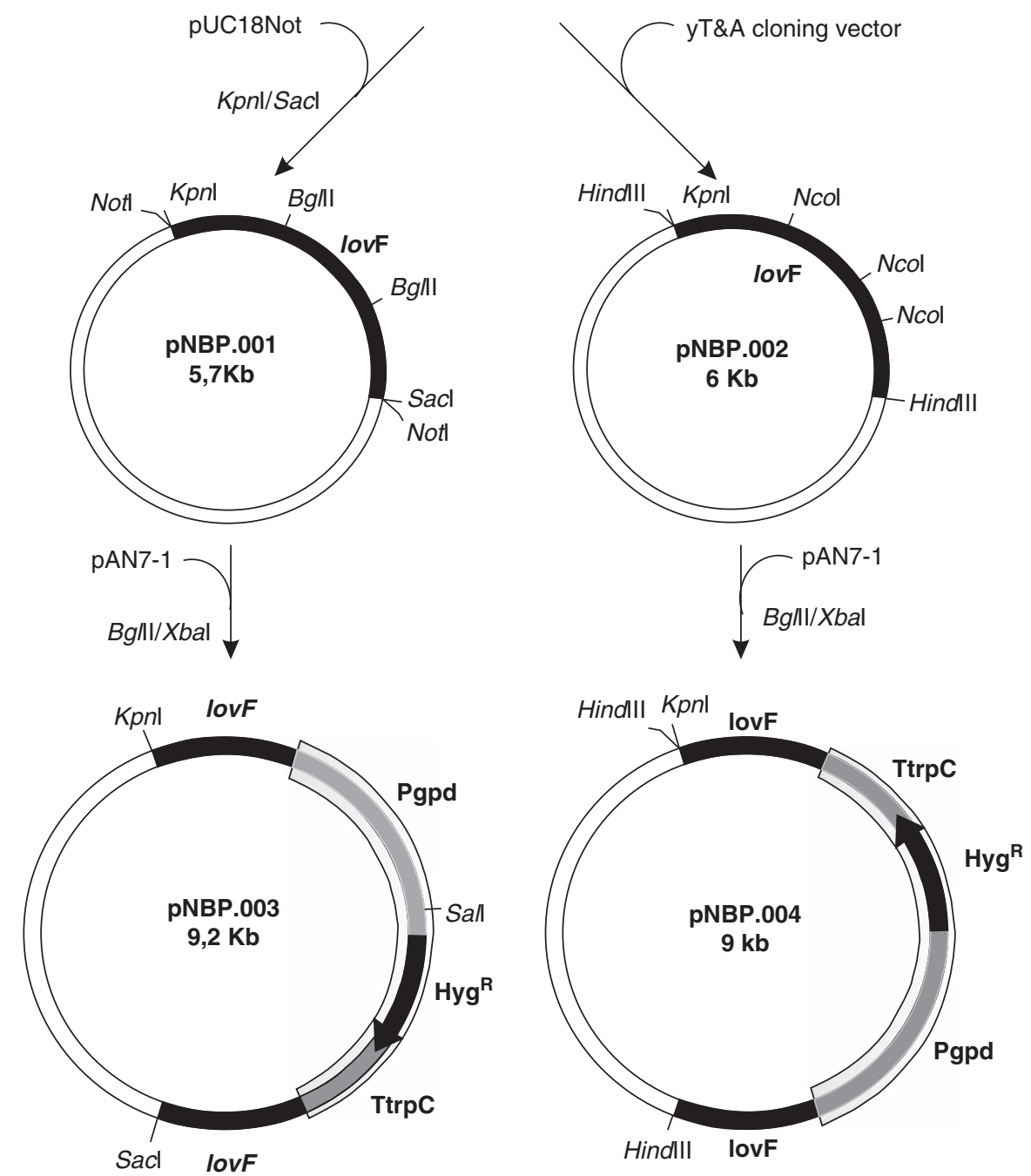

Figure 1 Scheme of construction of plasmids containing an IovF gene fragment amplified from DNA genomic of Neosartorya stramenia CECT 20742 (a) or the Aspergillus terreus ATCC 20542 (b). In both cases the lovF gene was disrupted by the hygromycin-resistance cassette. The PCR product was about 3 kb and amplified a central fragment of the gene.

with $0.1 \mathrm{M} \mathrm{NaOH}$ at $4{ }^{\circ} \mathrm{C}$ overnight to open the lactone and produce the acidic form. The assay was based on the spectrophotometric measurement of the decrease in absorbance at $340 \mathrm{~nm}$, which represents the oxidation of NADPH by the catalytic subunit of HMG-CoA reductase in the presence of the substrate $\mathrm{HMG}-\mathrm{CoA}$. The enzymatic reaction took place at $37^{\circ} \mathrm{C}$, in $96-$ well plates in the assay buffer ( $\mathrm{pH}$ 7.3) containing potassium phosphate monobasic $(50 \mathrm{~mm}), \mathrm{KCl}(1 \mathrm{~m}), \mathrm{BSA}\left(2 \mathrm{mg} \mathrm{ml}^{-1}\right)$ and dithiothreitol (5 mM). Total reaction volume was $200 \mu \mathrm{l}$ and concentration of DMSO was adjusted in each well up to $10 \mu$ l. Samples, DMSO, HMG-CoA and HMG-CoA reductase, were added to the wells following the order mentioned. The reaction was initiated with the addition of NADPH in all wells at the same time and immediately. Plates were introduced in a multiwell plate spectrophotometer set at $37^{\circ} \mathrm{C}$ and $340 \mathrm{~nm}$ with a kinetic program to read every $40 \mathrm{~s}$ up to $20 \mathrm{~min}$. A blank and a control well were included in each experiment. The $\mathrm{IC}_{50}(50 \%$ inhibitory concentration) was calculated through the trimmed SpearmanKarber method (Version 1.5) introducing the values of the enzymatic activity (\% of the control).

\section{Cell cultures}

Human hepatoma HepG2 and neuroblastoma SK-N-MC cells were obtained from American Type Culture Collection (coded as HB-8065 and HTB-10, respectively). Cells were routinely grown in MEM supplemented with $10 \%$ fetal bovine serum, $2 \mathrm{~mm}$ L-glutamine, $1 \mathrm{~mm}$ sodium pyruvate, $0.1 \mathrm{~mm}$ nonessential amino acids and $0.05 \mathrm{mg} \mathrm{ml}^{-1}$ gentamicin. Cells were grown in $175 \mathrm{~mm}^{2}$ flasks at $37{ }^{\circ} \mathrm{C}$ in a humidified atmosphere of $95 \%$ air and $5 \% \mathrm{CO}_{2}$. Cells were plated out after trypsinization in 96-well plates (Corning, Corning, NY, USA) at the density of $4 \times 10^{4}$ cells per well and incubated $24 \mathrm{~h}$. For cholesterol measurement assays, cells were pre-incubated in serum-free media for $8 \mathrm{~h}$ just before $20 \mathrm{~h}$ incubation with the active compounds at different concentrations in medium deprived of fetal bovine serum. ${ }^{13}$ Stocks for each compound ( $\left.10 \mathrm{~mm}\right)$ were prepared in sterile ultrapure water and incubated with $0.1 \mathrm{M} \mathrm{NaOH}$ at $4{ }^{\circ} \mathrm{C}$ overnight. After treatment, cells were washed twice with phosphate-buffered saline and lysed with $150 \mu \mathrm{l}$ of sodium phosphate monobasic buffer containing $0.5 \%$ Triton X-100 ( $\mathrm{pH} 7.0$ ). Complete lysates were obtained after freezingthawing the plates twice. ${ }^{14}$ 


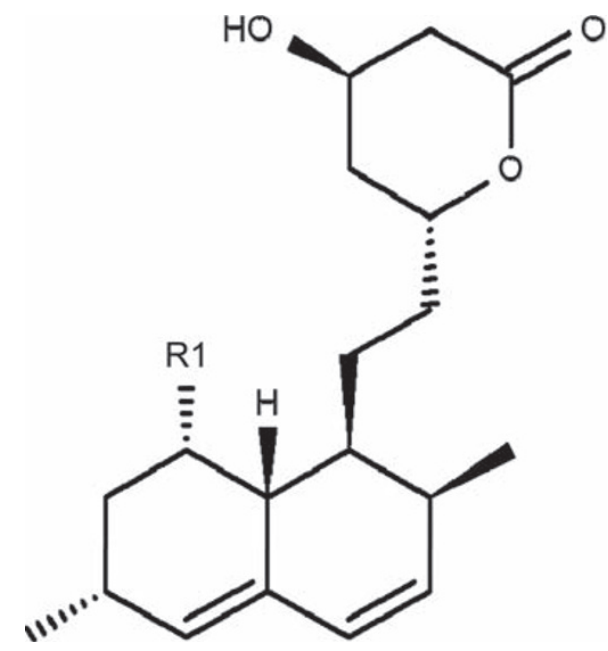

\begin{tabular}{|c|c|}
\hline Derivative & R1 \\
\hline Monacolin J & $\mathrm{OH}-$ \\
NST0003 & $\mathrm{CH}_{3}-\mathrm{CH}_{2}-\mathrm{CO}-$ \\
NST0004 & $\left(\mathrm{CH}_{3}\right)_{2}-\mathrm{CH}-\mathrm{CO}-$ \\
NST0005 & $\left(\mathrm{CH}_{3}\right)_{3}-\mathrm{C}-\mathrm{CO}-$ \\
NST0037 & $\left(\mathrm{CH}_{3}-\mathrm{CH}_{2}\right)_{2}-\mathrm{CH}-\mathrm{CO}-$ \\
NST0042 & $\mathrm{OH}-\mathrm{Ph}-\mathrm{CO}-$ \\
NST0056 & Linoleic-O- \\
\hline
\end{tabular}

Figure 2 Structure of the novel monacolin J derivatives. Different substitutions at R1 position are indicated in the table.

\section{Cholesterol assays}

Cell lysates $(25 \mu \mathrm{l})$ and a cholesterol standard curve ranging from 0.15 to $10 \mu \mathrm{g} \mathrm{ml}^{-1}$ were transferred to 96-well plates to determinate total cholesterol. $75 \mu \mathrm{l}$ of MES $0.05 \mathrm{M}$ (pH 6.5) containing cholesterol oxidase $\left(0.5 \mathrm{Uml}^{-1}\right)$, cholesterol esterase $\left(0.8 \mathrm{U} \mathrm{ml}^{-1}\right)$, peroxidase from horseradish type VI $\left(4 \mathrm{U} \mathrm{ml}^{-1}\right)$ and ampliflu red $\left(20 \mu \mathrm{g} \mathrm{ml}^{-1}\right)$ were added to the plates and allowed to react with the samples for $15 \mathrm{~min}$ at $37^{\circ} \mathrm{C}$. The fluorescence intensities were measured using a multiwell plate reader equipped with a filter set for excitation and emission at 530 and $580 \mathrm{~nm}$, respectively (Infinite 200; Tecan, Mannendorf, Switzerland). ${ }^{15}$ Protein was determined by the bicinchoninic acid method (Pierce, Rockford, IL, USA).

\section{Neuroprotection assays}

Cell death was evaluated using a modified MTT assay (WST-1; Roche Diagnostics, Barcelona, Spain). For assay, cells were treated with xanthine $10 \mu \mathrm{m} /$ xanthine oxidase $60 \mathrm{mU} \mathrm{ml}^{-1}$ (XXO), corresponding to the dose $\mathrm{LC}_{50}$ (the concentration that causes $50 \%$ cell death), to induce oxidative stress and cell injury along with monacolin $\mathrm{J}$ derivatives at increased concentrations during $24 \mathrm{~h}$. During the final $2 \mathrm{~h}$ of treatment, WST-1 was added to cells, in accordance with the manufacturer's instructions.

\section{RESULTS}

\section{Isolation and selection of statins-producing strains}

Soil and plant samples taken from different environments were processed by several isolation methods depending on the sample nature and origin. About 1500 fungal isolates were obtained and screened for antifungal activity against $C$. albicans. Four isolates were found to be able to produce lovastatin and another two were identified as mevastatin producers. One of the lovastatin-producing strains was selected as it produced twofold more monacolin J than lovastatin in liquid culture. This strain was identified by sequencing the $28 \mathrm{~S}$ rDNA D1/D2 region as N. stramenia and deposited in the Spanish Type Culture Collection (Valencia, Spain) as N. stramenia CECT 20742.

\section{Mutagenesis}

About 5000 colonies were screened after $N$-methyl- $N^{\prime}$-nitro- $N$-nitrosoguanidine treatment to check their antifungal activity. Colonies unable to produce growth inhibition zones were selected as putative monacolin J producers. These mutants were analyzed by UPLC-MS to determinate the production of monacolin $\mathrm{J}$ and lovastatin on solid cultures. One mutant (34-311) producing 10-fold more monacolin J than the parental strain was obtained.

\section{lovF gene disruption and monacolin J production}

The lovF locus of N. stramenia 34-311 strain was disrupted by the onestep gene disruption method. Protoplasts were transformed with both circular and linearized plasmids. After two rounds, 421 colonies were able to grow on SDA plates. Among them, 25 strains were selected as they did not produce inhibition growth halos in the bioassay (Figure 3a). UPLCMS analysis showed that 10 transformants produced more monacolin J than the parental strain and low amounts of lovastatin were present (Figure 3b). Homologous integration of the lovF-hyg ${ }^{\mathrm{R}}$ cassette in the endogenous $\operatorname{lov} F$ locus was presumed to have occurred in such transformants. Further hybridization analyses confirmed such event.

One strain (T-64) produced about sevenfold more monacolin J than the parental strain (Figure 3c). UPLC analysis and quantification using calibration curves showed that strain T-64 produced $0.76 \mathrm{~g}$ monacolin $\mathrm{J}$ ( $\beta$-hydroxy acid and lactone forms) per liter after $172 \mathrm{~h}$ of incubation whereas the parental strain reached $0.10 \mathrm{gl}^{-1}$.

\section{Semisynthesis of monacolin $\mathbf{J}$ derivatives}

Monacolin J extracted and purified from N. stramenia T-64 culture broths was used as a lead to obtain novel derivatives by semisynthesis at lab scale. Figure 2 shows some of the molecules produced by introducing different side chains at the C8 hydroxyl group. The resulting structures were confirmed by NMR analysis. For all compounds, the final purity was higher than $99.4 \%$.

HMG-CoA reductase inhibition by monacolin $\mathrm{J}$ derivatives

To analyze the hypocholesterolemic effect of the compounds, we evaluated their ability to inhibit the enzymatic activity of the ratelimiting enzyme HMG-CoA reductase and determined the $\mathrm{IC}_{50}$ (Figure 4). These studies showed that NST0037 inhibited the enzyme similar to simvastatin, being the most potent inhibitor with $\mathrm{IC}_{50}$ ranging in nanomolar. A second group of compounds (NST0003, NST0004 and NST0005) also inhibited the enzyme, but with poorer potencies than simvastatin. Finally, NST0042 and NST0056 showed the lowest inhibition of the enzyme.

\section{Hypocholesterolemic effects of monacolin J derivatives on human} hepatocytes

To further evaluate the hypocholesterolemic effect of the compounds, we determined total cholesterol in hepatoma (HepG2) cell line (Figure 5). For this purpose, cells were incubated with the same 

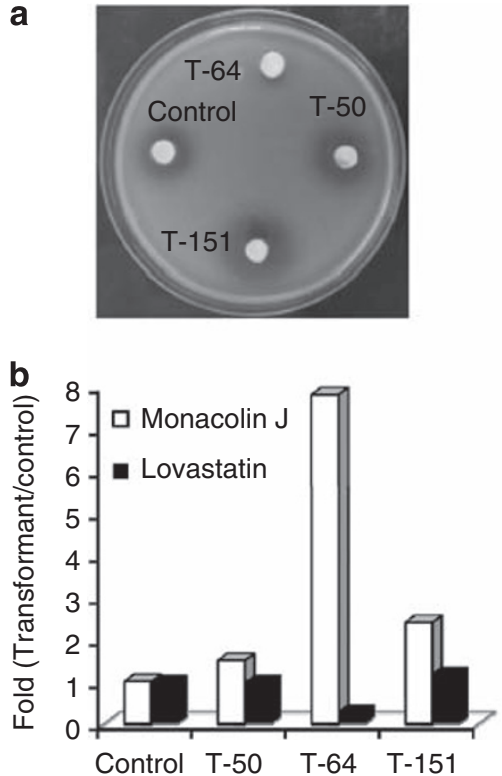

C

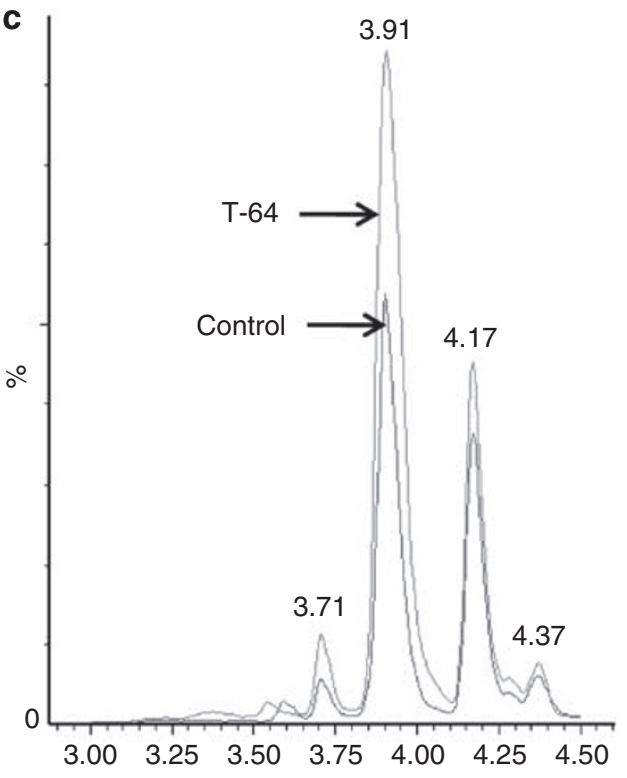

Figure 3 Production of monacolin $\mathrm{J}$ and lovastatin by some transformants and the parental strain (Neosartorya stramenia 34-211). (a) Bioassay for antifungal activity. (b) Statins production of transformants versus the parental strain. (c) UPLC-SIR-MS analysis after cultivation at $28^{\circ} \mathrm{C}$ for 7 days. Samples were previously diluted (1:4) in mobile phase. Peaks eluting at 3.91 and 4.17 min correspond to monacolin J ( $\beta$-hydroxy acid and lactone), respectively. Chromatograms corresponding to transformant T-64 and the parental strain are indicated by arrows.

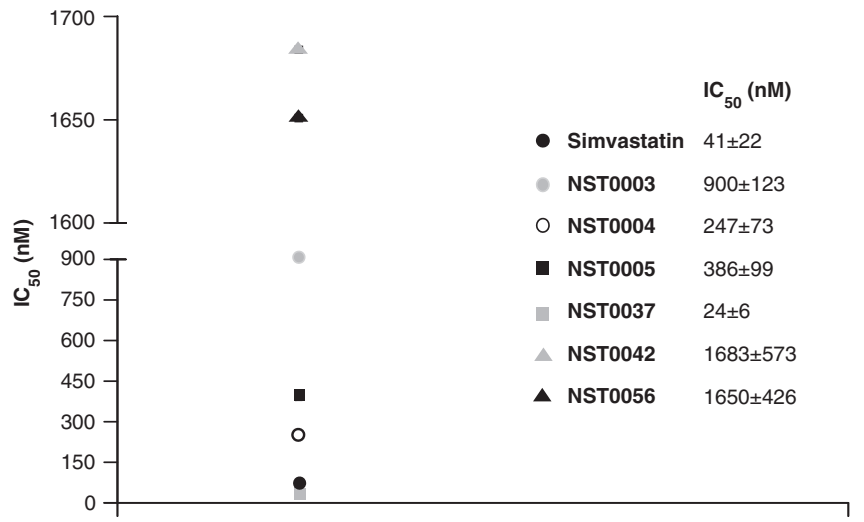

Figure 4 In vitro inhibition of HMG-CoA reductase activity by monacolin J derivatives. The capacity of inhibition of HMG-CoA reductase was evaluated in vitro by measuring the decrease in absorbance at $340 \mathrm{~nm}$, which represents the oxidation of NADPH by the catalytic subunit of HMG-CoA reductase in the presence of the substrate HMG-CoA. Enzyme activity (\% of the control) was determined for each compound concentration (10 concentrations used) and $\mathrm{IC}_{50}$ was calculated through trimmed Spearman-Karber method (Version 1.5). Data are the mean \pm s.d. of four independent experiments.

concentration $(1 \mu \mathrm{M})$ of the derivatives and total cholesterol measured. NST0004, NST0005 and NST0037 exerted a statistically significant reduction of intracellular cholesterol similar to the one exerted by simvastatin. On the contrary, NST0003, NST0042 and NST0056 did not present a statistically significant hypocholesterolemic effect, at least at the selected dose.

Protection by monacolin J derivatives of the oxidative-stressinduced neuron cell death

To evaluate the potential neuroprotective effect of the monacolin J derivatives, we performed a study of these compounds in comparison

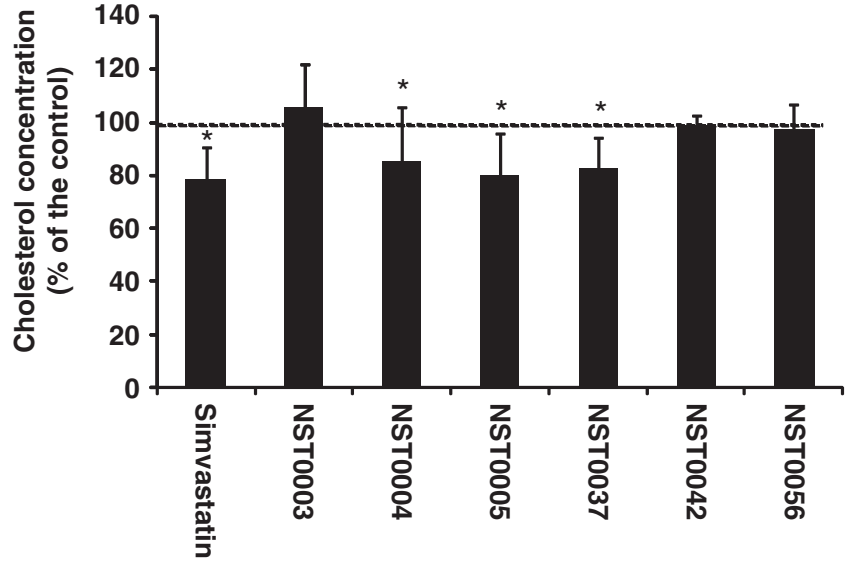

$[1 \mu \mathrm{M}]$

Figure 5 Hypocholesterolemic effects of monacolin $\mathrm{J}$ derivatives on human hepatocytes. Total cholesterol was related to untreated HepG2 cells (\%) after $20 \mathrm{~h}$ of incubation with $1 \mu \mathrm{m}$ of the monacolin $\mathrm{J}$ derivatives or simvastatin in absence of fetal bovine serum. Cholesterol levels were determined through fluorometric methods and normalized by protein concentration. Data are the mean \pm s.d. of, at least, two independent experiments performed in triplicate. ${ }^{*} P<0.05$, compared to untreated cells (Student's $t$-test).

to simvastatin. Neuron cell death was caused by oxidative stress, by incubating the SK-N-MC cells with XXO (xanthine $10 \mu \mathrm{m} /$ xanthine oxidase $60 \mathrm{mU} \mathrm{ml}^{-1}$ ). Protective effects of compounds were evaluated by incubation of the monacolin J derivatives (range of concentrations from 1 to $100 \mu \mathrm{M}$ ) together with $\mathrm{XXO}$, and cell viability assayed (Figure 6). Simvastatin protected from the oxidative-stress-induced neuron cell death in the range from 1 to $40 \mu \mathrm{M}$, although NST0037 was the most protective compound assayed, with a $75 \%$ of maximal 


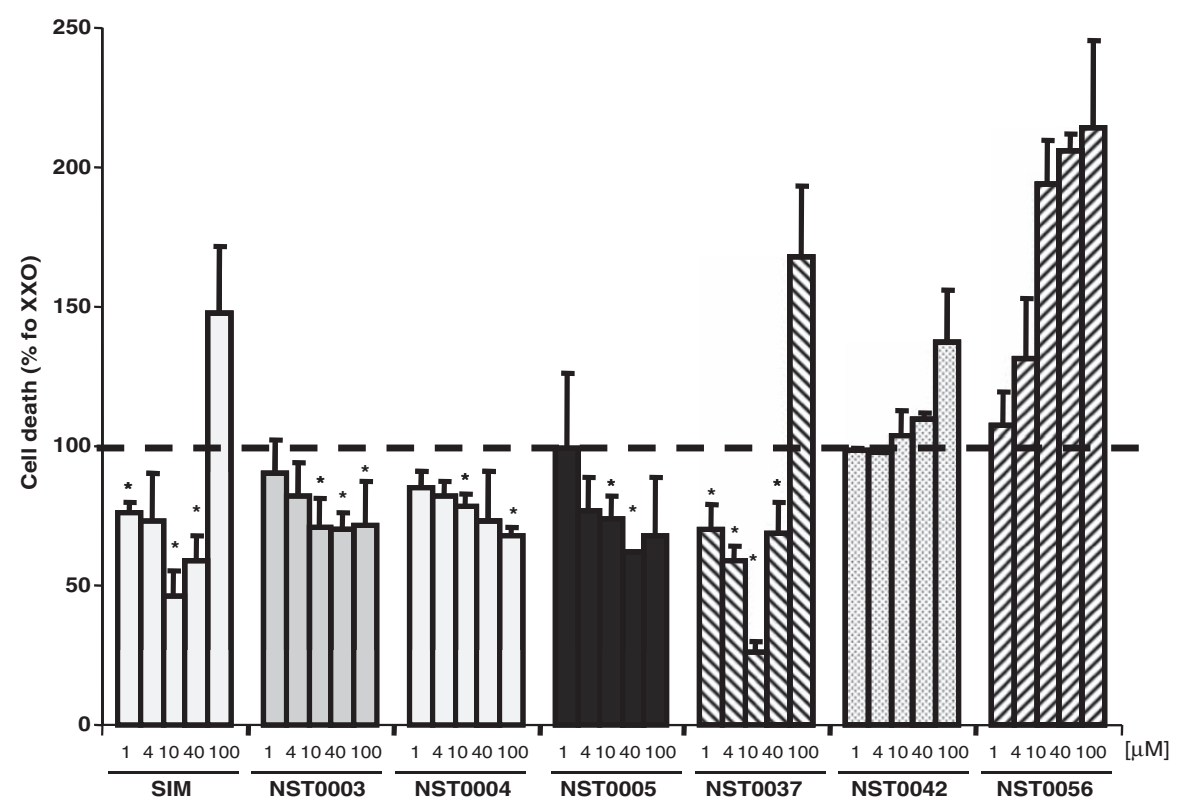

Figure 6 Neuroprotective effects of monacolin J derivatives against oxidative-stress-induced neuron cell death. Neuroblastoma cells were treated with XXO ( $10 \mu \mathrm{m}$ xanthine and $60 \mathrm{mU} \mathrm{ml}^{-1}$ xanthine oxidase) to induce oxidative stress and cell injury. The monacolin J derivatives were assayed at several concentrations for $24 \mathrm{~h}$. Cell death was determined by using the WST-1 assay. The data represent the percentage of XXO-induced cell death (mean \pm s.d.) of three independent experiments performed in triplicate. SIM, simvastatin ${ }^{*} P<0.05$, compared to XXO-treated cells (Student's $t$-test).

protection at $10 \mu \mathrm{M}$ (maximum protection of simvastatin $[10 \mu \mathrm{M}]=55 \%)$. NST0003, NST0004 and NST0005 also presented a good protective profile $(30 \%[40 \mu \mathrm{M}], 32 \%[100 \mu \mathrm{M}]$ and $38 \%[40 \mu \mathrm{M}]$, respectively), whereas NST0042 and NST0056 did not show neuroprotective effects at any assayed concentration.

\section{DISCUSSION}

Current industrial processes to produce natural-derived semisynthetic statins, including simvastatin, suffer from the need of producing monacolin J from lovastatin by chemical hydrolysis. Such processes are time consuming, need expensive chemical reagents and used organic solvents. Biotechnological methods have also been explored as the use of esterases for deacetylation of lovastatin, ${ }^{16}$ although costs are somehow expensive and long incubation times are required. Production of monacolin J by fermentation would overcome all these hurdles leading to an easier, more economical and more environmental friendly process. Profitability of such process will mainly depend on monacolin J titers, which should be as high as those for lovastatin. We are currently focused on such task and so far ongoing studies with small bioreactors have already improved monacolin J titers obtained in flasks by threefold (data not shown).

Statins are the most well-known plasma cholesterol-lowering drugs in the market. In addition to this effect, these compounds have also been reported to prevent stroke and development of peripheral vascular disease, ${ }^{17}$ as well as antithrombotic and anti-inflamatory effects. ${ }^{18}$ Other potential uses of these drugs may be hypertension and immune response. ${ }^{19,20}$ Very recently, results in experimental animal models showed that lower cholesterol levels slow the expression of Alzheimer's pathology, ${ }^{21}$ and it has been reported that the intake of statins is associated with a decreased incidence of $\mathrm{AD}{ }^{22}$ Furthermore, it has been shown that hypercholesterolemia accelerated $\mathrm{AD}$ pathology in transgenic animal models, ${ }^{23}$ being also an early risk factor for $\mathrm{AD}$ in epidemiology studies. ${ }^{24,25}$ These data point out the possibility that treating human patients with these cholesterol-lowering drugs might either reduce the risk of developing $\mathrm{AD}$ or help to treat it.

The complex association between cholesterol metabolism and $\mathrm{AD}$ is beginning to be strongly established, ${ }^{26}$ as several issues linked to lipid homeostasis have been identified as risk factor for $\mathrm{AD}$, including high levels of lipoproteins and hypercholesterolemia. Moreover, the use of some cholesterol-lowering drugs such as statins seems to correlate with a reduced risk for dementia. On the basis of the possible benefits of such cholesterol-lowering statin therapy, we have designed and evaluated the activity of six novel statins on cholesterol modulation and neuroprotection against oxidative damage. The hypocholesterolemic effect of these compounds was first determined by measuring their intrinsic potency to inhibit HMG-CoA reductase activity. Only one derivative (designated as NST0037) showed an $\mathrm{IC}_{50}$, slightly lower than simvastatin. Therefore, this compound could be a new good candidate as hypocholesterolemic agent. Furthermore, analysis of total cholesterol in human hepatocytes revealed that not only NST0037 but also simvastatin, NST0004 and NST0005, significantly decreased the cholesterol levels. The main risk factor for $\mathrm{AD}$ is aging. As aging process seems to be related to reactive oxygen species and free radicals, the design of new drugs to prevent an increase of such oxidative products in the brain could be a potential therapeutic target in AD. Neuroprotective potential of our novel derivatives checked using an oxidative-stress-induced neuron cell death model showed that NST0037 was the best neuroprotectant. Simvastatin also seemed to be able to prevent cell death whereas NST0003, NST0004 and NST0005 showed a moderate neuroprotective profile when higher concentrations were applied.

\section{ACKNOWLEDGEMENTS}

We gratefully acknowledge Professor Valdivieso F for his comments and help during the preparation of the paper. We also thank Vazquez R, Vazquez JA, Molino M, Molina P, Bailon AB and Esteo C for technical support. This work 
was partially supported by research funds from the Spanish Ministry of Science and Innovation, Torres Quevedo Research Program (MICINN-PTQ) to Campoy S, Sierra S, Suarez B, Ramos MC, Burgos JS and Adrio JL.

1 Shindia, A. A. Mevinolin production by some fungi. Folia Microbiol. 42, 477-480 (1997).

2 Manzoni, M. \& Rollini, M. Biosynthesis and biotechnological production of statins by filamentous fungi and application of these cholesterol-lowering drugs. Appl. Microbiol. Biotechnol. 58, 555-564 (2002).

3 Solomon, A. \& Kivipelto, M. Cholesterol-modifying strategies for Alzheimer's disease. Expert Rev. Neurother. 9, 695-709 (2009).

4 Solomon, A. et al. Lipid-lowering treatment is related to decreased risk of dementia: a population-based study (FINRISK). Neurodegener. Dis. 7, 180-182 (2010).

5 Rockwood, K. et al. Use of lipid-lowering agents, indication bias, and the risk of dementia in community-dwelling elderly people. Arch. Neurol. 59, 223-227 (2002).

6 Jick, H. et al. Statins and the risk of dementia. Lancet 356, 1627-1631 (2000).

7 Tobert, J. A. New developments in lipid-lowering therapy: the role of inhibitors of hydroxymethylglutaryl coenzyme A reductase. Circulation 76, 534-538 (1987).

8 Kennedy, J. et al. Modulation of polyketide synthase activity by accessory proteins during lovastatin biosynthesis. Science 284, 1368-1372 (1999).

9 Hong, C. I. et al. Process for preparing simvastatin. US patent 6833461B2. (2004).

10 Lee, J et al. Process for the preparation of simvastatin. PCT US patent 20050080275. (2005).

11 Punt, P. J. et al. Transformation of Aspergillus based on the hygromycin B resistance marker from Escherichia coli. Gene 56, 117-124 (1987).

12 Fierro, F. et al. Mutants blocked in penicillin biosynthesis show a deletion of the entire penicillin gene cluster at a specific site within a conserved hexanucleotide sequence. Appl. Microbiol. Biotechnol. 44, 597-604 (1996).
13 Hozumi, Y. et al. In vitro study of the effect of raloxifene on lipid metabolism compared with tamoxifen. Eur. J. Endocrinol. 143, 427-430 (2000).

14 Gamble, W. et al. Procedure for determination of free and total cholesterol in microor nanogram amounts suitable for studies with cultured cells. J. Lipid. Res. 19, 1068-1070 (1978).

15 Mizoguchi, T. et al. A method of direct measurement for the enzymatic determination of cholesteryl esters. J. Lipid Res. 45, 396-401 (2004).

16 Morgan, B. et al. Methods for making simvastatin and intermediates. US patent 20080182303. (2008).

17 Maron, D. J., Fazio, S. \& Linton, M. F. Current perspective on statins. Circulation 101, 207-213 (2000).

18 Vaughman, C. J., Gotto, A. M. \& Basson, C. T. The evolving role of statins in the management of atherosclerosis. J. Am. Coll. Cardiol. 35, 1-10 (2000).

19 Chong, P. H., Seeger, J. D. \& Franklin, C. Clinically relevant differences between the statins: implications for therapeutic selection. Am. J. Med. 111, 390-400 (2001).

20 Meier, C. R. et al. HMG-CoA reductase inhibitors and the risk of fracture. JAMA 283 3205-3210 (2000).

21 McGuinness, B. \& Passmore, P. Can statins prevent or help treat Alzheimer's disease? J. Alzheimers Dis. 20, 925-933 (2010).

22 Wolozin, B. et al. Re-assessing the relationship between cholesterol, statins and Alzheimer's disease. Acta Neurol. Scand. 185(Suppl), 63-70 (2006).

23 Refolo, L. M. et al. Hypercholesterolemia accelerates the Alzheimer's amyloid pathology in a transgenic mouse model. Neurobiol. Dis. 7, 321-331 (2000).

24 Puglielli, L., Tanzi, R. E. \& Kovacs, D. M. Alzheimer's disease: the cholesterol connection. Nat. Neurosci. 6, 345-351 (2003).

25 Tan, Z. S. et al. Plasma total cholesterol level as a risk factor for Alzheimer disease: the Framingham Study. Arch. Intern. Med. 163, 1053-1057 (2003).

26 Harris, J. R. \& Milton, N. G. Cholesterol in Alzhaeimer's disease and other amyloidogenic disorders. Subcell Biochem. 51, 47-75 (2010). 